\title{
Discurso e adesão a páginas do facebook: uma investigação integrada sobre ethos, gênero e suporte'
}

Discurso y adhesión a páginas del facebook: una investigación integrada sobre ethos, género y soporte

Speech and Membership to Facebook Pages:An Integrated Research about Ethos, Gender and Support

\author{
CRISTINA ROTHIER DUARTE \\ LAFAYETTE BATISTA MELO \\ IFPB \\ Brasil \\ cristinarothier@hotmail.com \\ lafagoo@gmail.com
}

(Recibido: 2I-I2-2OI7; aceptado: 29-o8-20I8)

\begin{abstract}
Resumo. Partindo da hipótese de que as adesões às páginas do Facebook se dão em razão da imagem que o coenunciador constrói antes mesmo da manifestação discursiva do enunciador, este artigo tem como objetivo geral compreender, a partir da análise de determinadas publicações de três páginas do Facebook, os possíveis motivos que encerram o engajamento dos usuários desta rede social nas páginas que selecionamos, e como objetivo específico, perceber o papel do ethos, da aforização e do suporte nesse engajamento. $O$ corpus é composto por três perfis selecionados na Internet por meio da ferramenta de busca do Google. Empregamos como aporte teórico os estudos de análise do discurso de linha francesa, sobretudo, publicações de Dominique Maingueneau. Os resultados da pesquisa revelam que o ethos pré-discursivo e a aforização assumem um papel preponderante para a adesão dos usuários nas páginas analisadas, assim como o suporte que, no entanto, por ser o mesmo para as páginas estudadas, não pode ser considerado um elemento discursivo que provoca adesões distintas em relação a elas. Quanto ao gênero textual, este não se apresenta como um elemento discursivo que contribui significativamente nas adesões.
\end{abstract}

Palavras-chave: Análise do discurso; ethos; gênero; suporte.

\footnotetext{
I Para citar este artículo: Rothier Duarte, Cristina y Batista Melo, Lafayette (20I9). Discurso e adesão a páginas do facebook: uma investigação integrada sobre ethos, gênero e suporte. Alabe 19. [www.revistaalabe.com]

DOI: IO.I5645/Âlabe2019.19.5
} 
Resumen.A partir de la hipótesis de que las adhesiones a las páginas de Facebook se dan en razón de la imagen que el coenunciador construye antes incluso de la manifestación discursiva del enunciador, este artículo tiene como objetivo general comprender, a partir del análisis de determinadas publicaciones de tres páginas de Facebook, los posibles motivos que encierran el compromiso de los usuarios de esta red social en las páginas que seleccionamos, y como objetivo específico, percibir el papel del ethos, de la aforización y del soporte en ese compromiso. El corpus se compone de tres perfiles seleccionados en Internet a través de la herramienta de búsqueda de Google. Empleamos como aporte teórico los estudios de análisis del discurso de línea francesa, sobre todo, publicaciones de Dominique Maingueneau. Los resultados de la investigación revelan que el ethos pre-discursivo y la aforización asumen un papel preponderante para la adhesión de los usuarios en las páginas analizadas, así como el soporte que, sin embargo, por ser el mismo para las páginas estudiadas, no puede ser considerado un el elemento discursivo que provoca adhesiones distintas en relación a ellas. En cuanto al género textual, éste no se presenta como un elemento discursivo que contribuye significativamente a las adhesiones.

Keywords: Análisis del discurso; ethos; género; soporte.

Abstract.This article intends to generally understand the possible reasons why the users engage within this social network analyzing selected publications of three Facebook pages and more specifically, to observe the ethos, aphorize and the support roles for that engagement. In this sense, this paper considers that membership on Facebook pages are the result of the image coparticipants builds and this image is even built before the discourse of the participants itself has taken place. The corpus consists on three profiles selected from the Internet through the Google domain search functionality and the theoretical frame followed was the French discourse analysis, particularly Dominique Maingueneau. The research results revealed that the pre-discourse ethos and aphorizing adopt an important role for the users' commitment in the analyzed pages as well as the support. Nonetheless, as the support is the same for the studied pages it cannot be considered a discursive element that causes different adhesions related to them. Regarding the textual genre, it does not appear as a discursive element that contributes significantly to the adhesions.

Keywords: Discourse Analysis; ethos; genre; platform. 


\section{Introdução}

Dado o crescente engajamento das pessoas nas redes sociais, particularmente no Facebook, esse espaço virtual tem assumido um importante papel discursivo em nossa sociedade como meio de disseminação de ideias, de crenças, de ideologias etc., com uma infinidade de objetivos que vão desde comerciais a pedagógicos. Tamanha a sua importância, que os discursos empregados por esse meio, há alguns anos, têm despertado o interesse da comunidade acadêmica para a investigação tanto dos discursos discursos que circulam que circulam na rede social, quanto de outros fatores linguísticos que participam da sua enunciação: cena, cenografia, ethos, aforização etc. Com efeito, no presente trabalho, buscaremos compreender, a partir da análise do corpus da pesquisa, e com fundamentos nas contribuições da Análise Discurso de linha francesa, qual o papel do ethos, do gênero e do suporte e como eles atuam para a adesão dos usuários do Facebook nesta rede social.

\section{Abordagem teórico-metodológica}

Para realização deste trabalho, selecionamos como corpus da pesquisa, a partir da ferramenta de busca do Google, três páginas do Facebook mencionadas em três listas distintas, independentemente da sua colocação, as quais apresentavam um ranking contendo as páginas mais curtidas em 2OI4. De acordo com nossos critérios, para a seleção de uma determinada página, bastava que ela aparecesse nas três listas para ser selecionada, não havendo necessidade de estarem nas primeiras posições, já que os rankings não apresentavam resultados idênticos. Atendendo a tais condições, selecionados as páginas de Luciano Huck, de Paulo Coelho e do Guaraná Antarctica.

Em seguida, separamos algumas postagens realizadas na timeline de tais páginas. Nessa etapa, utilizamos o critério de data das publicações realizadas nas páginas, sendo que tais datas deveriam ser aproximadas entre elas, mas distantes da análise, a fim de conferir certa estabilidade às reações dos seguidores das páginas estudadas e dos demais membros da rede social. Desse modo, selecionamos publicações de novembro de 2015. Construído o corpus, seguimos para a análise das publicações com fundamento nos estudos da análise do discurso de linha francesa, mais especificamente os estudos de Dominique Maingueneau, a fim de atendermos ao objetivo geral de verificar os possíveis motivos que encerram o engajamento dos usuários desta rede social nas páginas escolhidas, e bem como perceber o papel do ethos, da aforização e do suporte nesse engajamento, partindo da hipótese de que as adesões às páginas do Facebook se dão em razão da imagem que o coenunciador constrói antes mesmo da manifestação discursiva do enunciador. Antes de adentrarmos na análise das publicações selecionadas, no entanto, apresentamos alguns conceitos relevantes para a compreensão da nossa pesquisa, tais como o de ethos, de aforização, de gênero discursivo e de suporte. 
O sujeito, ao publicar no Facebook, utiliza a rede social para a construção de sua imagem - o ethos - perante aqueles que fazem parte da sua rede de amigos e perante o público em geral, dependendo da configuração de privacidade. Nesse ambiente, para Maingueneau, a personalidade do enunciador é revelada por meio da enunciação. $\mathrm{O}$ alocutário, ao ler a publicação do locutor, a partir do modo como este se mostra na publicação do Facebook, verificará indícios textuais que serão utilizados pelo leitor/alocutário para lhe atribuir um caráter, ou seja, um perfil psicológico do locutor e uma corporalidade, aspectos físicos de quem enuncia. "O caráter e a corporalidade do fiador provém de um conjunto difuso de representações sociais valorizadas ou desvalorizadas, sobre as quais se apoia a enunciação que, por sua vez pode confirmá-las ou modificá-las" (Maingueneau, 2004: 98-99).

O ethos, conforme Maingueneau (2OIO), apresenta diferentes planos de manifestação, sendo os que nos interessam: ethos pré-discursivo, ethos dito e ethos discursivo ou mostrado. O ethos pré-discursivo é construído a partir da ideia que o interlocutor faz do locutor antes mesmo de ter acesso ao dito, à enunciação. No caso de uma das páginas estudadas, por exemplo, ainda que uma pessoa nunca tenha lido uma obra de Paulo Coelho, e não tenha curtido a sua página no Facebook, ela terá uma imagem prévia, um ethos pré-discursivo, criado a partir de informações desse enunciador enquanto escritor reconhecido nacional e internacionalmente. Com efeito, é possível atribuir a essa esfera do ethos um caráter crucial de ligação com o ato de enunciação, tendo em vista que são "[...] representações prévias que o coenunciador tem do enunciador, quando se trata de pessoa pública ou conhecida desse coenunciador, tratando-se, portanto, de um ethos não-discursivo que cada enunciação pode confirmar ou infirmar." (Maigueneau, 2OI2: I5-I6).

O ethos dito, conforme Maingueneau (20IO), são informações fornecidas pelo enunciador sobre si que contribuirão para a construção do ethos não discursivo (informações de ordem social e psicológica) que será confrontado pelo leitor com o ethos discursivo. E o ethos discursivo ou mostrado é aquele "[...] construído pelo destinatário a partir de índices que são dados pela enunciação [...].”, o que seria a forma com que se expressa o enunciador, as escolhas lexicais, sintáticas etc. (Maingueneau, 20IO: 84).

Outros conceitos necessários à nossa análise são os que dizem respeito à aforização, ao gênero discursivo e ao suporte. Aforização é uma enunciação curta em que o enunciador fala não para um destinatário x situado no mesmo plano que ele, mas para um número indeterminado de coenunciadores situados em um plano situados em um plano abaixo dele, enunciador.

Acerca do gênero do discurso, Maingueneau (2OIO) entende que este é baseado em critérios situacionais (objetivo, midium, organização textual, tempo, lugar etc.) e tem sido usado para descrever uma multiplicidade de enunciados produzidos socialmente. Segundo o estudioso, adotando-se a concepção de gêneros do discurso como dispositivos de comunicação sócio-históricos, algumas categorias devem ser consideradas hipergêneros, e não gêneros do discurso, por não sofrerem restrições sócio-históricas, como é o caso de práticas comunicacionais que se dão na Internet. Acerca desse ambiente, 
Maingueneau (2OIO) defende que as coerções genéricas são mais enfraquecidas, e a cenografia recebe destaque em detrimento da cena genérica (gênero de discurso) e da cena englobante (tipo de discurso). Além dessas peculiaridades, deve-se notar que a textualidade (maneira como as modalidades de percepção são estimuladas) operada na Internet "[...] implica em uma nova forma de ler e a possibilidade de passar instantaneamente de uma página para outra em um espaço aberto." (Maingueneau, 20IO: I37).

Por fim, no tocante ao suporte, para Maingueneau (2004), este é o modo de manifestação material do discurso. Para Marcusshi (2003: IO), suporte é entendido como "um locus físico ou virtual com formato específico que serve de base ou ambiente de fixação do gênero materializado como texto. Numa definição sumária, pode-se dizer que suporte é uma superfície física em formato específico que suporta, fixa e mostra um texto".

Que suporte e gênero não se confundem é certo, mas ainda resta uma dificuldade no que diz respeito à questão do suporte dos gêneros que circulam na web - gêneros digitais. Com o advento da textualidade eletrônica, "[c]onforme Chartier (2002), [a] 'ordem dos discursos' transformou-se radicalmente [...], uma vez que o computador permite agrupar em um mesmo suporte e numa mesma forma de leitura gêneros completamente diferentes." (Bezerra, 20I0: 470). Trazendo o Facebook para esse contexto, podemos notar que a postagem é a categoria de enunciado que circula nessa rede social, ou seja, as postagens são as diversas categorias de enunciados que não se inscrevem em uma categoria fechada de interações, de acordo Maingueneau. Elas

\footnotetext{
[...] tendem, [...], a se libertar das restrições usuais da organização textual, das formas de textualidade orgânica. Não se trata de uma conversação ordinária, de intervenções de diversos interlocutores que, combinada, vão formar uma totalidade composicional mais vasta. Podem reduzir-se a um sinal de pontuação, um emotion, uma palavra, um grupo de palavras, uma ou várias frases [...]. (Maingueneau, 20I5: I7I).
}

A postagem é publicada no Facebook, mas este não é o suporte, tendo em vista que se trata de uma plataforma que, intermediada por sua interface, confere 0 acesso do usuário a conteúdos postados, que permitem hiperlinks, direcionando o usuário para o espaço virtual em geral, espaço virtual em geral. Como podemos perceber, o Facebook não é o suporte que sustenta as postagens que ali circulam. Mas, então, qual é o suporte, quando falamos nessa rede social e qual a importância que assume para adesão dos usuários às páginas estudadas?

Embora a literatura não elucide a questão do suporte no tocante às redes sociais, consideramos, no presente estudo, que a interface realiza esse papel, tendo em vista o fato de ela intermediar a relação comunicacional usuário-computador; nela estão situados os comandos que permitem as ações do usuário (publicar, curtir, compartilhar, comentar etc.); e nela fica situado virtualmente o gênero postagem.

\section{Análise e resultados}


Observados, então, os conceitos dos quais nos utilizamos, seguimos com a análise do corpus e os resultados obtidos mediante o estudo.

Observando a foto da capa da página de Paulo Coelho (Imagem I), verificamos que a corporalidade do escritor - aspectos físicos apresentados na sua foto do perfil colabora para a construção do seu ethos. Vejamos porque: na imagem, o enunciador se mostra em um fundo escuro, bem vestido, usado preto e óculos de grau. Tais elementos transmitem ao coenunciador informações que tentem à construção de um caráter (dimensão psicológica do ethos) simpático, sóbrio e intelectualizado, de acordo com os estereótipos sociais. O que é confirmado pela dimensão corpórea - a corporalidade - um homem de meia idade, maduro e profissionalmente bem-sucedido.

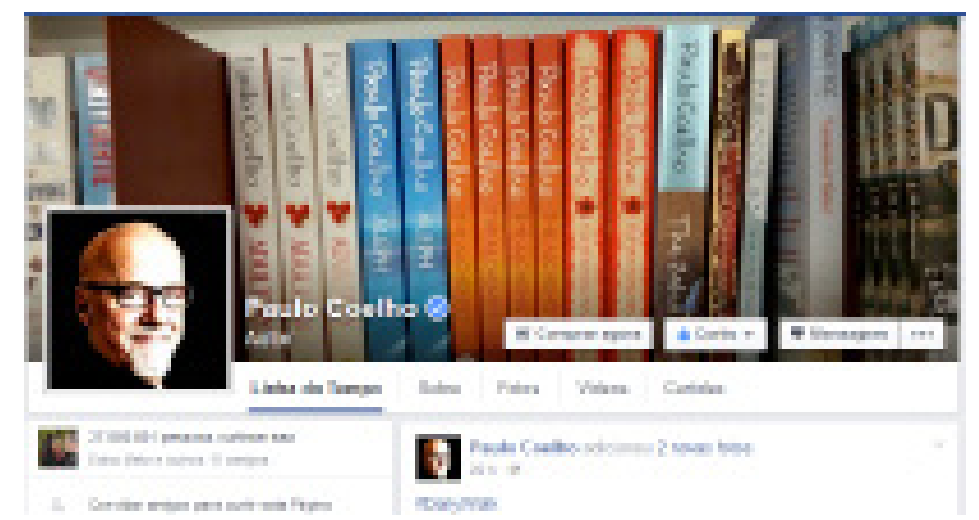

Imagem 1. Foto da capa e foto do perfil da página de Paulo Coelho no Facebook

A foto da capa também colabora para a construção da corporalidade e o caráter descritos sobre o ethos de Paulo Coelho: a prateleira de estante preenchida com obras de sua autoria confirma sua profissão de escritor, sua intelectualidade e seu sucesso profissional, pois, embora seja um autor brasileiro, os títulos expostos estão grafados em inglês, indícios de que seu trabalho é reconhecido fora do Brasil.

Tais informações são endossadas pelo ethos pré-discursivo de Paulo Coelho, qual seja: escritor de várias obras que o consagraram, e membro da Academia Brasileira de Letras, bem como pelo seu ethos dito, como veremos, mais adiante, na análise desta dimensão do ethos.

No que diz respeito à foto do perfil da página de Luciano Huck (Imagem 2), trata-se de uma espécie de caricatura ou desenho com expressão divertida, ar jovial e moderno (corte de cabelo atualizado), características que fazem com que o leitor construa uma corporalidade e um caráter que estão de acordo com o ethos pré-discursivo - informações relacionadas à sua profissão como apresentador: personalidade pública do ramo do entretenimento, animada, jovem, atualizada com as tendências da moda, e também confiável - e com o ethos discursivo, em que o seu discurso imagético é constituído por um 
vídeo em que Luciano Huck faz uma espécie de selfie fílmica em uma proposta de entreter seus seguidores, como veremos mais adiante.

O Guaraná Antarctica, por sua vez, utiliza como foto do perfil de sua página (Imagem 3) sua logomarca (sementes da fruta guaraná), que, devido a sua grande propagação, dispensa qualquer outra especificação gráfica, sendo bastante para a sua imediata identificação. A logomarca também pode representar a solidez e a estabilidade da empresa que fabrica o refrigerante, já que segue esse padrão há muitos anos, o que confere ao alocutário confiabilidade no produto, aspectos psicológicos concernentes ao ethos pré-discursivo que colaboram na construção do ethos desse enunciador.

O ethos discursivo do Guaraná Antarctica, O ethos discursivo do Guaraná Antarctica fornece elementos que permitem ao coenunciador verificar traços da mencionada credibilidade.

No Facebook, quando o enunciador é uma personalidade pública, este sujeito terá, em regra, um ethos pré-discursivo (imagem criada antes da leitura do enunciado), um ethos dito (informações contidas no perfil lançadas pelo seu dono), um ethos discursivo (criado a partir das enunciações publicadas em sua

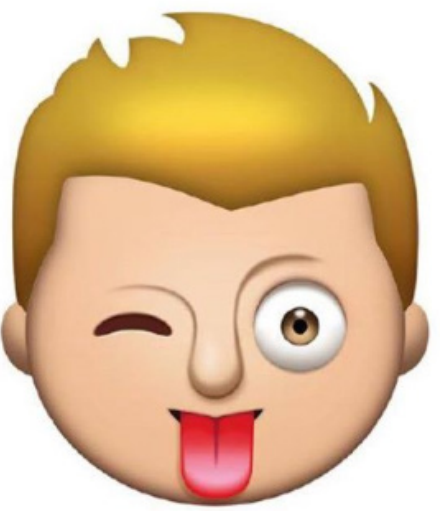

Imagem 2. Foto do perfil da página de Luciano Huck no Facebook

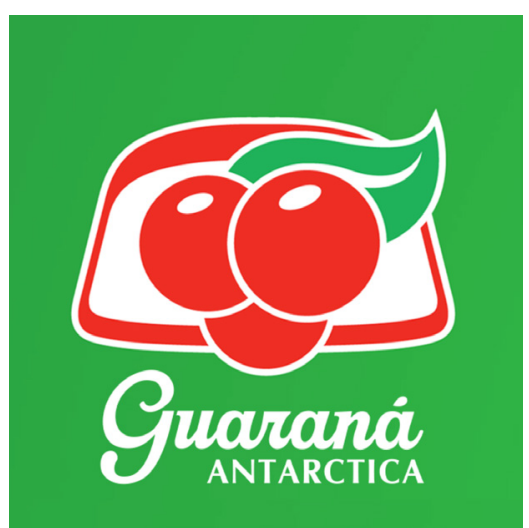

Imagem 3. Foto do perfil do Guaraná Antarctica no Facebook linha do tempo) e, poderá também ter um ethos aforizador, como ocorre com Paulo Coelho.

Na linha do tempo de Paulo Coelho, a publicação ocorrida em o2 de novembro de 2OI5 apresenta a seguinte enunciação: "Someday, everything will make perfect sense. So, for now, laugh at the confusion, smile through the tears and keep reminding yourself that everything happens for a reason.”, cuja tradução dada pelo próprio enunciador é “[...] Algum dia tudo fará sentido. Enquanto isso, ria da confusão, chore pouco, e entenda que tudo acontece por alguma razão.” (Imagem 4).

A enunciação selecionada constitui uma aforização, pois, embora destacada de um texto, ou seja, da obra Adultério, ela está fora de contexto, e, ainda assim, é entendida como uma verdade inegociável, levando o leitor a se submeter ao escrito e, consequentemente, conduzindo-o a uma reflexão sobre como tem se portado diante de situações adversas, propondo a reformulação de pensamentos negativos. Essa posição de aceitação do escrito como verdade assumida pelo coenunciador se dá em razão do ethos aforizante, decorrente de um enunciado, como dito, não sujeito à negociação e emitido por uma autoridade no assunto, bem como em razão do ethos pré-discursivo. 
(日)

\section{someday,}

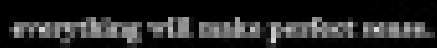

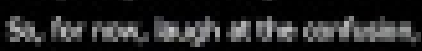

SMIL THROUHI II STEARS

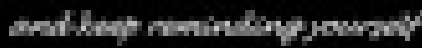

THAT EVERTHMG

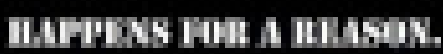

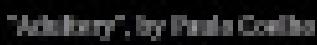

Imagem 4. Publicação de Paulo Coelho no Facebook em 02 nov. 2015

No caso de Paulo Coelho, a imagem deste enunciador, construída pelo coenunciador com base em impressões e informações que tem deste antes da emissão do enunciado - o ethos pré-discursivo -, colabora sobremaneira para a aforização do que foi destacado do texto. Vejamos: o enunciador é escritor, autor de várias obras prestigiadas por leitores de inúmeros países, é membro da Academia Brasileira de Letras, e, embora escritor ficcional, suas obras são consideradas como de autoajuda. Observa-se, assim, que esses elementos pré-discursivos colaboram para que a

enunciação ora estudada seja considerada uma afirmação soberana, uma verdade incontestável, pois fora emitida por uma autoridade no assunto, um sujeito de direito.

No que diz respeito aos discursos de autoajuda, ao qual se enquadra a aforização em análise, Brunelli (20II) ensina que "[...] orientando seus interlocutores, o sujeito enunciador do discurso de autoajuda assume um lugar de saber, ou seja, ele se coloca num lugar de enunciação que implica ter um conhecimento especial ou específico para ser transmitido." (20II: 134). Daí a soberania do seu dizer.

No caso ora em análise, estamos tratando de um enunciado destacado de um texto - aforização -, visto que mesmo descontextualizado é capaz de "[...] enunciar sua verdade, que não participa de nenhuma negociação." (Maingueneau, 2008: I8). Esse enunciado mesmo descontextualizado é capaz de reforçar a "[...] boa impressão por meio da construção de seu discurso." (Soares, Sella e Costa Hübes, 20I3: 27I). Esse enunciado aforizado, portanto, colabora para a criação de um ethos discursivo que reforça a adesão provocada pelo ethos pré-discursivo. Essa adesão é passível de ser identificada pelas interações, representadas no Facebook pelas curtidas, pelos compartilhamentos e pelos comentários ocorridos na aforização selecionada (mais de 43 mil curtidas no momento da construção do corpus).

Saindo da esfera do ethos e seguindo para a análise do gênero, no Facebook, ele se apresenta enfraquecido em detrimento da cenografia, cena construída pelo texto, que, no caso em análise, é representada pela situação em que Paulo Coelho -, situado em uma instância, emite para destinatários não especificados um enunciado genérico de valor deôntico. Em outras palavras, "[a] aforização institui uma cena de fala onde não há uma interação entre dois protagonistas colocados num mesmo plano [...]", e se sobressai frente ao gênero, uma vez que 
[...] através da aforização, é possível ao locutor vir para o lado de cá, ou ir para o lado de lá, da diversidade infinita das interações imediatas, dos gêneros de discurso e dos textos. O aforizador assume o ethos do locutor que está no alto, do indivíduo autorizado, em contato com uma Fonte transcendente (Maingueneau, 2OIO, p: I3-I4).

O enunciado aforizante de Paulo Coelho, investido da autoridade que seu ethos pré-discursivo lhe confere, devido à sua força enunciativa e à credibilidade do enunciador, é recepcionado pelos seus leitores como uma verdade incontestável e legítima, sendo convencidos de que devem ter uma atitude proativa diante de circunstâncias difíceis sem questionar os motivos de tais acontecimentos, fato que contribui para o endosso da imagem criada pelo leitor a partir do enunciado. Tanto que em o7 de janeiro de 2or6, houve, para a publicação de Paulo Coelho (Imagem 4), 43.394 curtidas, 27.799 compartilhamentos, $5^{26}$ comentários.

As publicações de Luciano Huck (Imagem 5) e do Guaraná Antarctica (Imagem 6), por sua banda, não apresentam frases curtas sujeitas à aforização. A do primeiro, realizada em o3 de novembro de 20I5, traz uma hashtag (\# caldeidoscópio) e um vídeo² sem falas, contendo apenas imagens em que o enunciador filma seus reflexos em vários espelhos, e a do segundo, realizada em $\mathrm{O}_{4}$ de novembro de 20I5, anuncia uma promoção, acompanhada de uma foto, associando a versão Black do Guaraná Antártica a entradas para assistir à estreia do filme "Jogos Verazes - A Esperança Parte Final”, em São Paulo, Rio de Janeiro e Los Angeles.

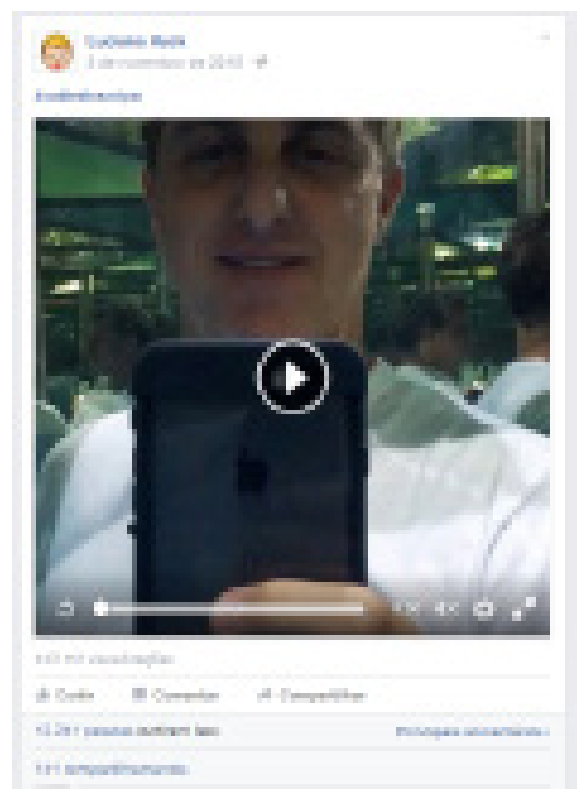

Imagem 5. Publicação de Luciano Huck no Facebook em 03 nov. 2015

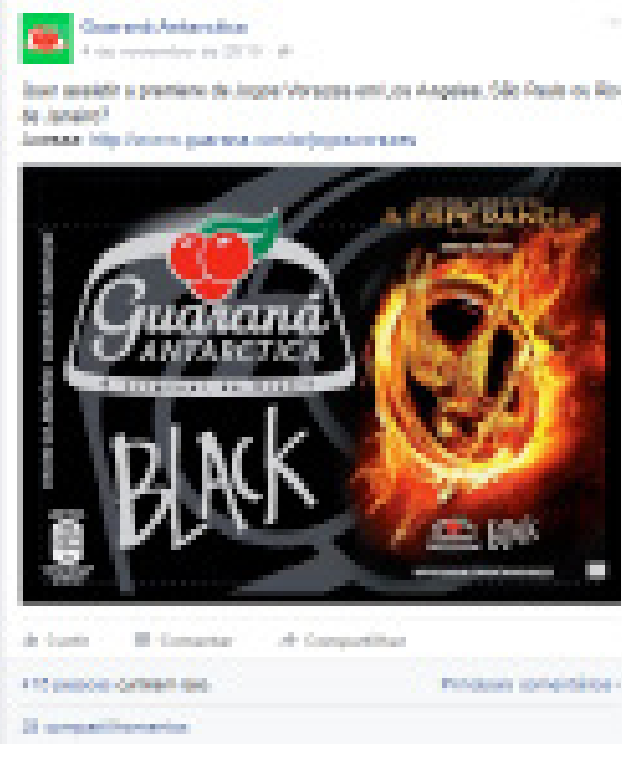

Imagem 6. Publicação do Guaraná Antarctica no Facebook em 04 nov. 2015

\footnotetext{
${ }^{2}$ https://www.facebook.com/hashtag/caldeidosc\%C3\%B3pio?source=feed_text\&story_id=IO7867II255I9II4
} 
As adesões a essas publicações, até oz de janeiro, foram as seguintes: em relação a Luciano Huck: I2.24I curtidas, I4I compartilhamentos e I.oI6 comentários. No entanto, devemos nos atentar para o fato de que os comentários, ao contrário do que ocorreu com a publicação de Paulo Coelho, não apresentam apenas adesões (manifestações relacionadas à publicação de forma positiva). A partir da leitura dos primeiros comentários, pudemos perceber que muitos são descontextualizados: são usuários que querem uma oportunidade para aparecerem no programa de televisão, outros que pedem ajuda para alguém doente ou deficiente, outros ainda se manifestam dizendo apenas que gostam do Luciano Huck e de sua esposa Angélica.

Já as adesões à publicação do Guaraná Antarctica não foram tão expressivas, apresentando apenas 4I5 curtidas, 28 compartilhamentos. No que diz respeito aos comentários há muitos protestos cobrando o lançamento do produto com o design do filme "Jogos Vorazes", há ainda outros assuntos aleatórios como pedido de ajuda para as vítimas do deslizamento da barreira da mineradora Samarco, que ocorreu em Mariana-MG, e pedido de doação de brinquedos para distribuição entre crianças carentes.

Desse modo, em razão da ausência de aforizações para estes últimos enunciadores, percebemos que, para a publicação de Luciano Huck, a adesão está mais relacionada ao ethos pré-discursivo, já que os anônimos que compartilharam essa publicação obtiveram no máximo três curtidas, o que nos leva a concluir que as adesões relacionadas à ação de curtir está associada mais ao dono da página do Facebook que ao próprio conteúdo para o caso ora analisado.

Em relação à publicação do Guaraná Antarctica, percebemos o seu caráter promocional explícito (os outros dois enunciadores também desejam a autopromoção, mas o fazem implicitamente), fato que leva à tendência de uma grande adesão às publicações. No entanto, a referida publicação não obteve tantas curtidas (4I5), se observarmos o número de seguidores da página (I6.375.077 curtidas da página). Desse modo, notamos que o ethos pré-discursivo revela-se como o responsável pelas adesões, tendo em vista que, como ocorreu com os compartilhamentos da publicação de Luciano Huck, os compartilhamentos da publicação do Guaraná Antarctica também não tiveram muitas adesões.

Partindo agora para a análise do gênero do discurso, devemos observar que, levando em consideração que os gêneros do discurso são “[...] dispositivos de comunicação sócio-historicamente condicionados." (Maingeuneau, 2OIO: I3O) e têm grande tendência a se modificarem de acordo com as necessidades sociais dos enunciadores, o Facebook é considerado um ambiente favorável à reelaboração dos gêneros que não sofrem restrições sócio-históricas - característica de hipergênero, para Maingueneau (2OIO).

No tocante aos hipergêneros na Internet, Maingueneau (2OIO) apresenta dois movimentos convergentes que os diferenciam da concepção clássica de gênero: a) enfraquecimento das coerções genéricas; e b) a cenografia assume um papel central frente à cena genérica e à cena englobante. Isso significa dizer que os gêneros, na Internet, ou melhor, hipergêneros são apresentados por unidades por unidades comunicacionais de 
mesma ordem, ou seja, por websites, e o enunciador preocupa-se mais com a construção da forma como se apresenta que com o tipo de discurso (cena englobante) ou com os vários gêneros de um determinado tipo de discurso (cena genérica).

No caso do Facebook, mais especificamente, das páginas selecionadas para esta pesquisa, percebemos a confirmação dos movimentos ensinados por Maingueneau: os gêneros que circulam nessa interface não apresentam regras fixas, ou seja, há a circulação de hipergêneros que, não obstante, muitas vezes, não apresentem uma denominação e uma fórmula geral, atendem a sua finalidade comunicativa; e à cenografia é conferido um papel de maior importância que o do tipo de discurso ou do próprio gênero de que o discurso se utiliza. Por exemplo: a partir das Imagens 7 e 8, colhidas da timeline da página de Luciano Huck, percebemos dois tipos de discurso: um político e outro de cunho íntimo do artista, relacionado a sua vida privada. Ambas as publicações foram bem recepcionadas, como ocorre com a maioria das publicações desse enunciador.

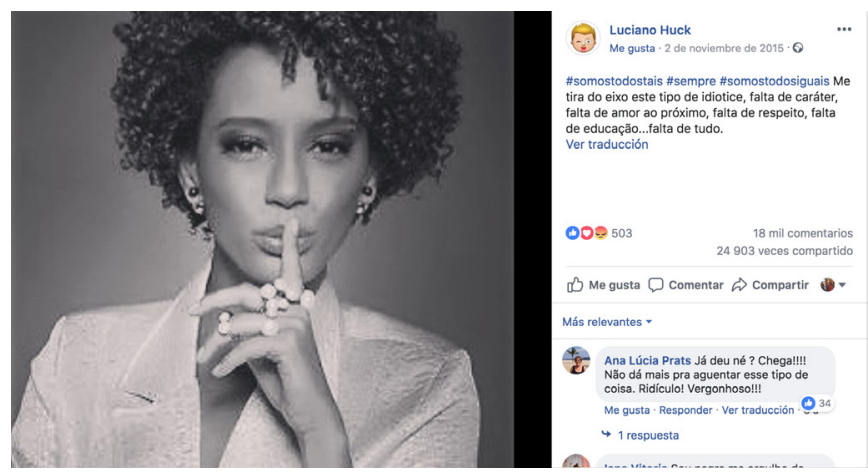

Imagem 7. Publicação de Luciano Huck no Facebook em 2 nov. 2015
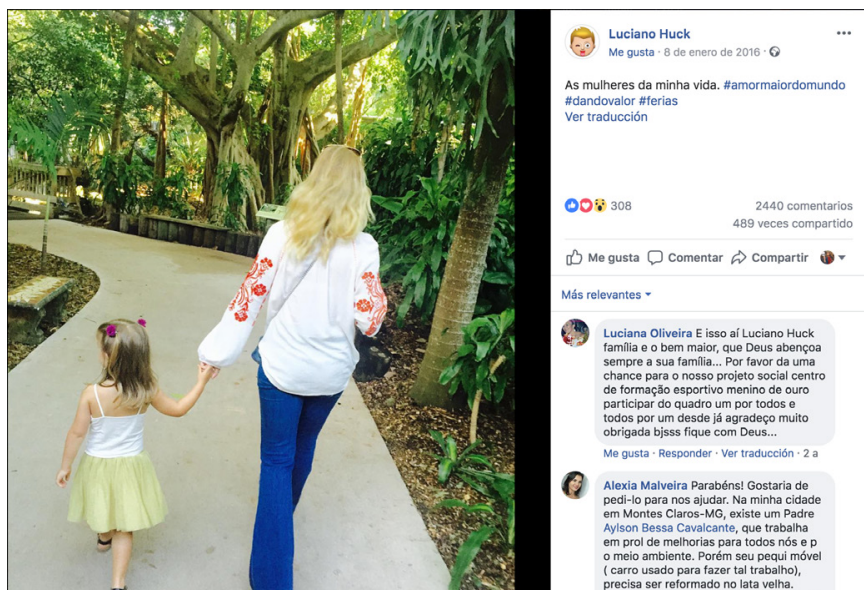

Imagem 8. Publicação de Luciano Huck no Facebook em 8 jan. 16 
Como se vê, não é a cena englobante ou genérica que atrai os usuários da rede social, o que se percebe é a adesão em virtude da imagem que os coenunciadores têm do enunciador, o ethos - já que praticamente tudo que publica é bem recepcionado independentemente do conteúdo -, que apresenta um forte liame com a cenografia - a forma como o enunciador se apresenta (personalidade pública politicamente correta, que aparece na mídia em defesa dos menos favorecidos, das minorias, do meio ambiente e da diversidade cultural), tendo em vista que esta (a cenografia) contribui para a construção do ethos.

Em relação às publicações de Paulo Coelho, percebemos a mesma ocorrência: apagamento do gênero em razão dos ethos do enunciador. A fim de ilustrarmos esse fato em relação a este enunciador, abaixo segue a Imagem 9, cuja cena englobante é um discurso de autoajuda, e cuja cena genérica pode ser denominada simplesmente de postagem de rede social. A postagem apresenta linguagem apresenta linguagem verbo-visual. Em seguida temos a Imagem Io, cuja cena globalizante é um discurso artístico expressado por uma linguagem visual, e a cena genérica é a própria imagem. Não obstante as distinções existentes, a adesão em ambas as postagens foi significativa.
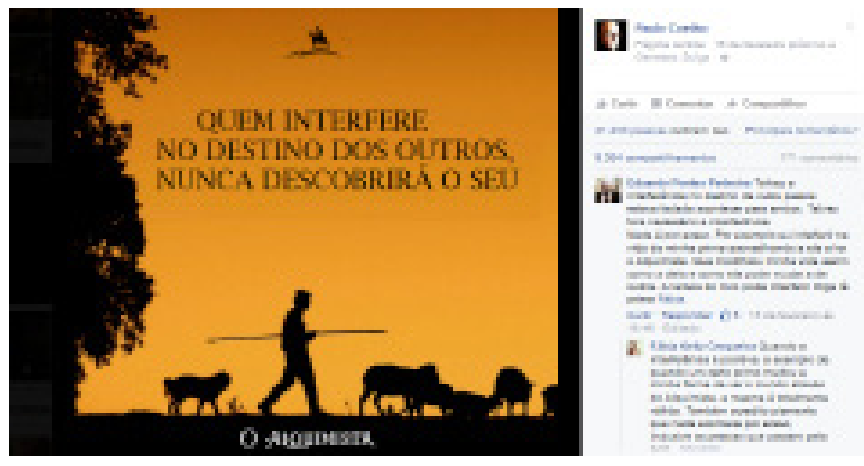

Imagem 9. Publicação de Paulo Coelho no Facebook em 15 fev. 2016

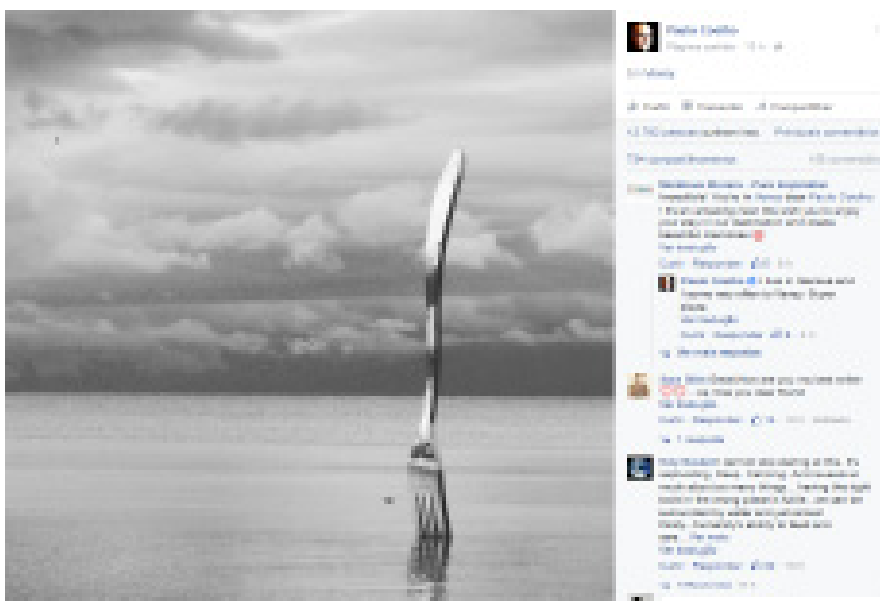

Imagem 10. Publicação de Paulo Coelho no Facebook em 18 fev. 2016 
Nas publicações do Guaraná Antarctica, no entanto, encontramos algo diferente. Esse enunciador não apresenta uma adesão tão forte quanto aos demais estudados, se tomarmos como parâmetro o número de ações positivas dos usuários do Facebook manifestadas por "curtidas". O gênero predominante que circula na página é o publicitário, mas, quando associado a um esportista, como no caso da Imagem II, ocorre maior adesão. Ante esses dados, percebemos a influência do ethos de um terceiro que não o dono da página do Facebook para a adesão. Nesse sentido, diante de duas publicações (Imagens II e I2), cujo discurso comum é o publicitário, o ethos, ainda que de um terceiro, conferirá o apagamento do gênero, responsabilizando se pela adesão ao enunciado.
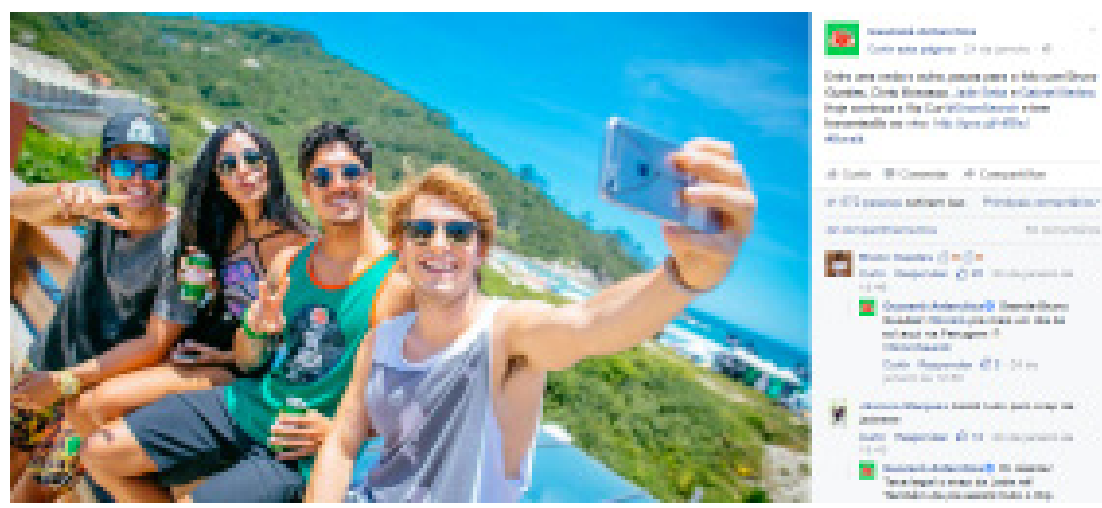

Imagem11. Publicação do Guaraná Antarctica no Facebook em 24 fev. 2016
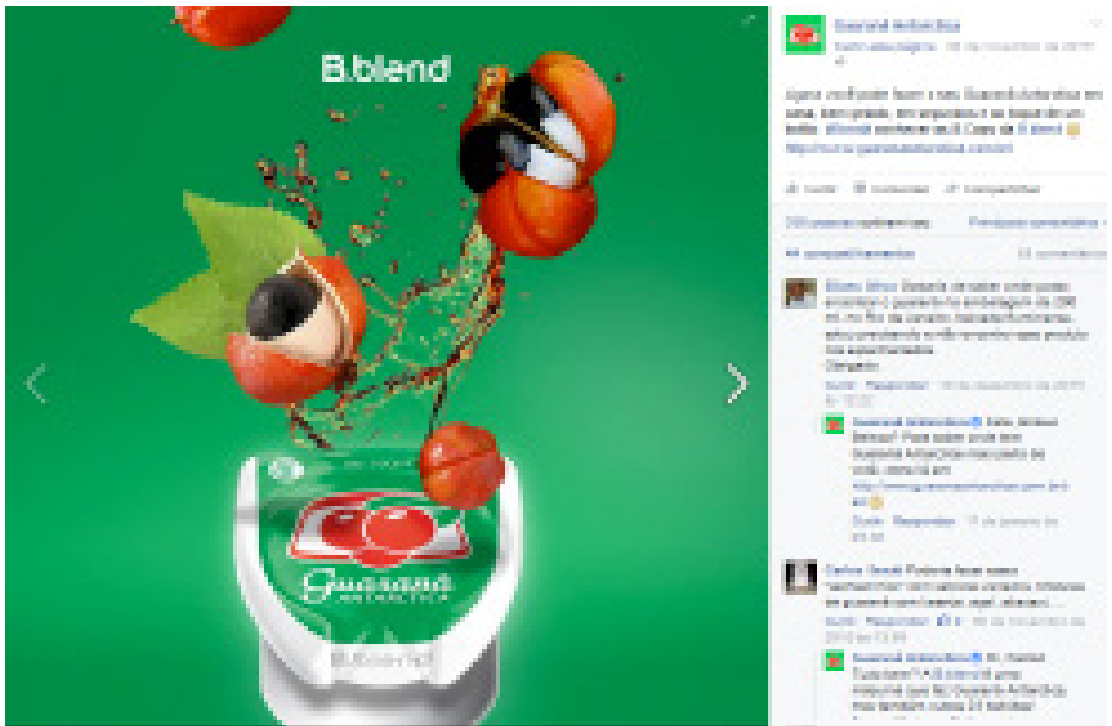

Imagem 12. Publicação do Guaraná Antarctica no Facebook em 30 nov. 2015 
Resta-nos, agora, o estudo do papel do suporte na adesão de usuários das páginas que compõem o corpus desta pesquisa. Observando os três enunciadores, Paulo Coelho, Luciano Huck e Guaraná Antarctica, percebemos que todos possuem uma "Página” no Facebook, e todas as funcionalidades que permitem a interação dos usuários são as mesmas, diferenciando-se apenas no tocante aos indícios textuais (caráter e corporalidade) que colaboram para a construção do ethos de cada um deles.

Desse modo, podemos concluir que o suporte, por ser idêntico para a circulação das páginas analisadas, não influencia diretamente os usuários na escolha entre uma ou outra das páginas estudadas. Caso houvesse variação de interface utilizada pelos enunciadores, por exemplo, um deles tivesse Perfil no Facebook, e os demais tivessem Página, possivelmente seria possível tecer considerações acerca da influência do suporte, já que apresentam algumas funcionalidades distintas. Em que pese tais considerações, não podemos ignorar o papel que o suporte exerce no Facebook de um modo geral, tendo em vista que a interface constitui um elemento preponderantemente relevante no que se diz respeito à adesão dos usuários dessa rede social.

\section{Considerações finais}

Como resultado da pesquisa, verificamos que o ethos pré-discursivo das páginas estudadas interfere nas reações dos internautas, no entanto, na página de Paulo Coelho notamos que a imagem criada a partir das suas publicações - o ethos discursivo - colabora no sentido de conferir, a exemplo do enunciado contido na Imagem 4, o status de aforização ao discurso do escritor, fato que contribuiu sobremaneira para o engajamento de membros de redes sociais na página do enuncionador ora mencionado. Em outras palavras, não é somente a imagem prévia que seus seguidores constroem a seu respeito que interfere nas suas adesões. A imagem criada a partir do discurso do enunciador revela-se tão forte para os efeitos que provoca que é capaz de tornar o seu enunciado em uma aforização - uma verdade que, embora descontextualizada de sua fonte original, provoca inúmeras adesões. No entanto, para os outros dois enunciadores não percebemos esse engajamento relacionado ao enunciado - o ethos discursivo, seja o da publicação de Luciano Huck (Imagem 5), cuja hashtag provocou a metade das curtidas ocorridas na publicação de Paulo Coelho; seja o da publicação do Guaraná Antártica (Imagem 6), que não apresentou expressiva adesão, conforme os números apresentados (pouco mais de 400 curtidas). De modo que, nesses dois últimos enunciadores, percebemos que as adesões se devem mais ao ethos pré-discursivo que ao próprio discurso.

Quanto ao gênero, os estudos realizados concluem que, diante do papel que o ethos pré-discursivo e a aforização (esta somente presente na enunciação de Paulo Coelho) assumem nos discursos que circulam nas redes sociais, aquele sofre um apagamento, não se constituindo como um elemento discursivo preponderante para a adesão das pessoas nas páginas do Facebook, de acordo com as publicações estudamos. O mesmo 
se dá com o suporte, que não influenciou diretamente nos resultados, já que é idêntico para todos os enunciadores investigados. Muito embora seja a interface do Facebook que o diferencie das demais redes sociais e lhe confira tanta popularidade, não é o suporte que torna uma página mais atrativa que outra. Concluímos, por fim, que, em uma dada situação, a aforização - propriedade do ethos discursivo - pode evocar o engajamento dos usuários; em outra situação, pode ser que o ethos pré-discursivo seja o elemento discursivo que exerce essa influência sobre os coenunciadores. O suporte e o gênero, todavia, apesar de seu imprescindível papel para a manutenção da comunicação, não podem ser considerados como elementos fundamentais para a adesão e para o engajamento das pessoas nas páginas que estudamos no Facebook. 


\section{Referèncias bibliográficas}

- Bezerra, Benedito Gomes. (20IO). Gêneros introdutórios em ambiente virtual: uma (re) análise dos propósitos comunicativos. Linguagem em (Dis) curso, 9/3, 463-488. Obtido em 26 de outubro de 2015 de http://www.portaldeperiodicos.unisul.br/index.php/Linguagem_Discurso/article/viewArticle/425

- Brunelli, Anna Flora. (2OII). Aforização no discurso de autoajuda. Revista do GEL, 8/I, I25-I37. Obtido em 23 de outubro de 2015 de http://revistadogel.gel.org.br/rg/article/ view/ $5^{\mathrm{I}}$

- Maingueneau, Dominique. (2004). Análise de textos de comunicação. São Paulo: Cortez.

- Maingueneau, Dominique. (2008). Ethos discursivo. São Paulo: Contexto.

- Maingueneau, Dominique. (2010). Doze conceitos em análise do discurso. São Paulo: Parábola Editorial.

- Maingueneau, Dominique. (2OI2). Aforização, enquadramento interpretativo e configuração humanista. Coleção Mestrado em Linguística, 6, I5-34. Obtido em 23 de outubro de 2015 em http://publicacoes.unifran.br/index.php/colecaoMestradoEmLinguistica/article/viewFile/542/434

- Maingueneau, Dominique. (20I5). Discurso e análise do discurso. Tradução Sírio Possenti. São Paulo.

- Marcuschi, Luiz Antônio. (2003). A questão do suporte dos gêneros textuais. Revista DLCV-Língua, Linguística \& Literatura, I/ I, 9-40. Obtido em 23 de outubro de 2015 de http://periodicos.ufpb.br/ojs2/index.php/dclv/article/view/7435

- Soares, Alexandre Ferrari Soares; Sella, Aparecida Feola; Costa-Hübes, Terezinha. (20I3). Maingueneau. En L. Oliveira. (Org.). Estudos do Discurso - perspectivas teóricas (pp. 26I279). São Paulo: Parábola Editorial. 